\title{
ISMIP-HEINO experiment revisited: effect of higher-order approximation and sensitivity study
}

\author{
Ondřej SOUČEK, ${ }^{1}$ Zdeněk MARTINEC ${ }^{1,2}$ \\ ${ }^{1}$ School of Cosmic Physics, Dublin Institute for Advanced Studies, 5 Merrion Square, Dublin, Ireland \\ E-mail: ondrej@cp.dias.ie \\ ${ }^{2}$ Department of Geophysics, Faculty of Mathematics and Physics, Charles University in Prague, V Holešovičkách 2, \\ 18000 Prague 8, Czech Republic
}

\begin{abstract}
We revisit the results of the ISMIP-HEINO benchmark by first analyzing the differences in various model outputs using a wavelet-based spectral technique. Second, the ISMIP-HEINO benchmark experiments are recomputed with a novel numerical ice-sheet model based on the SIA-I algorithm that enables both the shallow-ice and a higher-order approximation of the ice-flow equations to be performed. To assess the significance of the higher-order approximation in the ISMIP-HEINO experiment, a numerical sensitivity study for the shallow-ice approximation (SIA) simulations is also carried out. A high sensitivity of the SIA model response to surface temperature perturbations is found. We conclude that the variations in ISMIP-HEINO results are due to the differences in (1) simulated basal temperatures and (2) numerical treatment of the basal sliding condition.
\end{abstract}

\section{INTRODUCTION}

The ISMIP-HEINO (Ice Sheet Model Intercomparison Project-Heinrich Event INtercOmparison) benchmark, which was proposed by R. Calov and R. Greve (http://www.pik-potsdam.de/calov/heino_project.html), attempts to validate a mechanism for Heinrich events (HE) (Heinrich, 1988; Bond and others, 1992; Broecker, 1994; Andrews, 1998; Clarke and others, 1999) by a hypothesis of an intrinsic dynamic-thermodynamic icesheet instability caused by successive thermal activations and deactivations of an ice stream over a soft sedimentary area. Such a mechanism was supported by previous findings of MacAyeal (1993), Payne (1995), Greve and MacAyeal (1996), Hindmarsh and Le Meur (2001) and Calov and others (2002); however, several different mechanisms were also proposed (e.g. Meier and Post, 1987; Hulbe and others, 2004). To assess the robustness of the earlier conclusions, the ISMIP-HEINO experiment was designed to mimic the conditions in Hudson Bay and Hudson Strait, Canada, in a simplified way by assuming they form a soft sedimentary basin over which the basal sliding (if it occurs) is considerably faster than in the surrounding ice-covered basal areas overlying a coarser bedrock. The climatic forcing (i.e. the surface temperatures and accumulation/ablation rates) and the geothermal heat flux are specified for the model simulations and constrain the ice-sheet evolution. The ice-sheet model is thermomechanically coupled and the sliding condition at the base allows for local switching from 'stick' to 'slip' behavior, depending upon local basal temperatures. The 'Heinrich' ice-sheet instability is then associated with the activation of a fast-sliding ice stream over the sedimentary basin once the basal melting conditions are met. The induced massive discharge of ice mass results in successive thinning of the ice cover over the sedimentary basin and eventually allows for refreezing of the base. In that case, the whole process is repeated (quasi-)periodically.

Our aim is to recompute the ISMIP-HEINO results with a novel numerical ice-sheet model that enables the implementation of the shallow-ice $(\mathrm{SI})$ and higher-order $(\mathrm{HO})$ approximations of the ice-flow equations. We assess the effect of the $\mathrm{HO}$ approximation compared to that of the SI alone.

We briefly review the ISMIP-HEINO experiment set-up and discuss the previous results. We then introduce our novel thermomechanical numerical ice-sheet model and validate its ability to successfully compute thermomechanically coupled ice-sheet simulations in a series of European Ice-Sheet Modelling Initiative (EISMINT) benchmark experiments. The ISMIP-HEINO simulations are then carried out in the SI mode. Of particular importance is ISMIP-HEINO experiment $\mathrm{T} 1$, performed in the $\mathrm{HO}$ mode by employing the SIAI algorithm (Souček and Martinec, 2008), where the role of the inclusion of longitudinal stresses in the momentum equations, rheology and sliding law is quantified. We then investigate the robustness of our ISMIP-HEINO results by computing the sensitivity of the model output with respect to small perturbations in surface temperatures. We use wavelet analysis to quantify the differences in these results.

\section{ISMIP-HEINO SET-UP}

The set-up of the ISMIP-HEINO experiment is given in http://www.pik-potsdam.de/calov/heino/he_setup_2006_ 11_02.pdf. The model domain is depicted in Figure 1. The region of 'Hudson Bay' and 'Hudson Strait' $(A B C D \cup E F G H)$ represents the sedimentary basin, and the rest of the base is assumed to be coarser bedrock. The accumulation rate, $b$, prescribed as a linear function of the distance, $d$, from the domain center, increases from a minimal value, $b_{\min }$ at $d=0$, to a maximal value, $b_{\max }$ at $d=D$ :

$$
b=b_{\min }+\frac{b_{\max }-b_{\min }}{D} \times d .
$$

Immediate calving is prescribed for distances $d>D$. The surface temperature is defined as

$$
T_{\text {surf }}=T_{\min }+S_{\mathrm{T}} d^{3},
$$

where $S_{\mathrm{T}}$ is the surface temperature gradient, and a homogeneous geothermal heat flux is prescribed at the 


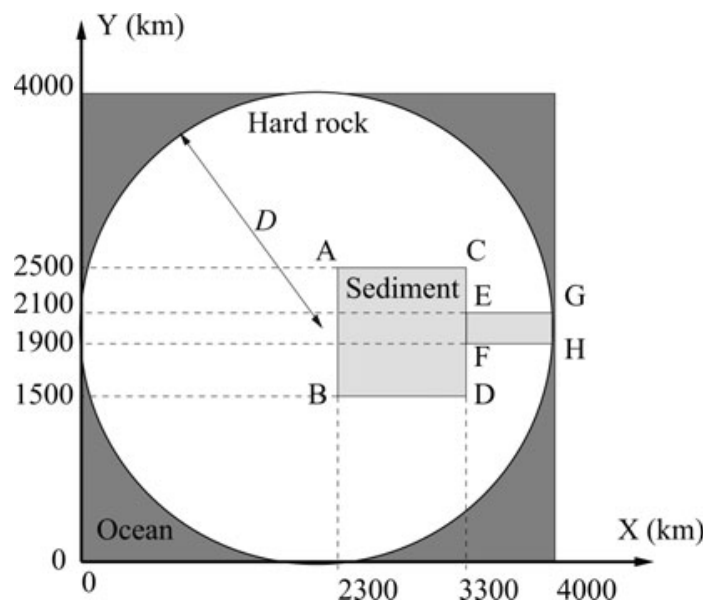

Fig. 1. Model domain of the ISMIP-HEINO experiment. The ocean is shaded in dark gray; the sedimentary basin is the light gray square $A B C D$ and rectangle EFGH, representing the 'Hudson Bay' and 'Hudson Strait', respectively. The remaining land (in white) corresponds to coarser bedrock.

glacier base. The ice rheology is governed by Glen's flow law (Glen, 1955). The values of the physical parameters involved are given in Table 1 . The sliding law differs according to the region. For the sedimentary basin (in Hudson Bay and Hudson Strait) the basal sliding velocity, $\mathbf{v}_{\mathrm{b}}$, obeys a linear relation

$$
\mathbf{v}_{\mathrm{b}}=-\frac{C_{\mathrm{S}}}{\rho g} \boldsymbol{\tau}_{\mathrm{b}}, \quad \text { if } T_{\mathrm{b}}^{\prime}=T_{0},
$$

while for the coarser part the sliding is assumed to be Weertman-type:

$$
\mathbf{v}_{\mathrm{b}}=-\frac{C_{\mathrm{R}}}{\rho g} \frac{\left|\boldsymbol{\tau}_{\mathrm{b}}\right|^{2}}{N_{\mathrm{b}}^{2}} \boldsymbol{\tau}_{\mathrm{b}}, \quad \text { if } T_{\mathrm{b}}^{\prime}=T_{0},
$$

where $T_{b}^{\prime}$ is the absolute temperature at the glacier base relative to the pressure melting,

$$
T_{\mathrm{b}}^{\prime}=T_{\mathrm{b}}+\beta p,
$$

with $\beta$ the Clausius-Clapeyron constant, $p$ the pressure, $N_{\mathrm{b}}=-t_{z z}^{\mathrm{b}}$ the normal stress at the base, $\boldsymbol{\tau}_{\mathrm{b}}=-\left(t_{x z}^{\mathrm{b}}, t_{y z}^{\mathrm{b}}, 0\right)$ the tangential basal stress, $t_{\alpha \beta}$ the components of the Cauchy stress tensor at the base, and $C_{S}, C_{R}$ the sliding parameters. If temperature is below the pressure-melting point, the frozenbed condition is applied:

$$
\mathbf{v}_{\mathrm{b}}=\mathbf{0} \quad \text { if } T_{\mathrm{b}}^{\prime}<T_{0} .
$$

For all simulations, the horizontal resolution of the numerical model is $50 \mathrm{~km}$, which corresponds to $81 \times 81$ gridpoints in the horizontal plane. The vertical resolution is specified by 61 equally spaced gridpoints in the 'stretched' vertical coordinates (when the glacier geometry is mapped to a layer of uniform thickness). The time-step is 0.25 years. The ice sheet is built up from initial ice-free conditions over a time interval $0-200 \mathrm{ka}$. A total of eight model simulations are examined: ST, T1, T2, S1, S2, S3, B1 and B2, which may be divided into the following four groups, according to the quantity varied in the experiment:

The reference simulation ST, for the set-up given in

\begin{tabular}{|c|c|}
\hline Parameter & Value \\
\hline Density of ice, $\rho$ & $910 \mathrm{~kg} \mathrm{~m}^{-3}$ \\
\hline Gravity acceleration, $g$ & $9.81 \mathrm{~m} \mathrm{~s}^{-2}$ \\
\hline Power-law exponent, $n$ & 3 \\
\hline Flow-enhancement factor, $E$ & 3 \\
\hline Rate factor, $A\left(T^{\prime}\right)$ & $A_{0} \exp \left(-Q / R T^{\prime}\right)$ \\
\hline Pre-exp. factor, $A_{0}, \begin{array}{l}T^{\prime} \leq 263.15 \mathrm{~K}: \\
\\
T^{\prime}>263.15 \mathrm{~K}:\end{array}$ & $\begin{array}{c}3.61 \times 10^{-13} \mathrm{~s}^{-1} \mathrm{~Pa}^{-3} \\
1.73 \times 10^{3} \mathrm{~s}^{-1} \mathrm{~Pa}^{-3}\end{array}$ \\
\hline Activation energy, $Q, T^{\prime} \leq 263.15 \mathrm{~K}$ : & $60 \mathrm{~kJ} \mathrm{~mol}^{-1}$ \\
\hline$T^{\prime}>263.15 \mathrm{~K}:$ & $139 \mathrm{~kJ} \mathrm{~mol}^{-1}$ \\
\hline Sliding parameter for hard rock, $C_{R}$ & $10^{5} \mathrm{a}^{-1}$ \\
\hline Sliding parameter for soft sediment, $C_{\mathrm{S}}$ & $500 a^{-1}$ \\
\hline Geothermal heat flux, $q_{\mathrm{geo}}$ & $4.2 \times 10^{-2} \mathrm{~W} \mathrm{~m}^{-2}$ \\
\hline Melting point at atmospheric pressure, $T_{0}$ & $273.15 \mathrm{~K}$ \\
\hline Heat conductivity of ice, $\kappa$ & $2.1 \mathrm{~W} \mathrm{~m}^{-1} \mathrm{~K}^{-1}$ \\
\hline Specific heat capacity of ice, $c$ & $2009 \mathrm{Jg}^{-1} \mathrm{~K}^{-1}$ \\
\hline Clausius-Clapeyron gradient, $\beta$ & $8.7 \times 10^{-4} \mathrm{Km}^{-1}$ \\
\hline Latent heat of ice, $L$ & $3.35 \times 10^{5} \mathrm{~J} \mathrm{~mol}^{-1} \mathrm{~K}^{-1}$ \\
\hline Universal gas constant, $R$ & $8.314 \mathrm{~J} \mathrm{~mol}^{-1} \mathrm{~K}^{-1}$ \\
\hline Seconds per year & $31556926 \mathrm{sa}^{-1}$ \\
\hline Domain radius, $D$ & $2000 \mathrm{~km}$ \\
\hline Minimum surface mass balance, $b_{\min }$ & $0.15 \mathrm{~m}$ ice eq. $\mathrm{a}^{-1}$ \\
\hline Maximum surface mass balance, $b_{\max }$ & 0.3 m ice eq. $\mathrm{a}^{-1}$ \\
\hline Minimum surface temperature, $T_{\min }$ & $233.15 \mathrm{~K}$ \\
\hline Surface temperature gradient, $S_{\mathrm{T}}$ & $2.5 \times 10^{-9} \mathrm{Kkm}^{-3}$ \\
\hline
\end{tabular}
Table 1.
Table 1. Values of the physical parameters for ISMIP-HEINO reference simulation ST (from Calov and others, 2010)

Temperature variation experiments $(\mathrm{T} 1, \mathrm{~T} 2): T_{\min }$ varied by $\pm 10 \mathrm{~K}: T_{\min }=223.15 \mathrm{~K}(\mathrm{~T} 1)$ and $T_{\min }=243.15 \mathrm{~K}$ (T2).

Surface accumulation variation experiments (B1, B2): $b_{\min }=0.075 \mathrm{ma}^{-1}, b_{\max }=0.15 \mathrm{ma}^{-1}$ (B1) and $b_{\min }=$ $0.3 \mathrm{ma}^{-1}, b_{\max }=0.6 \mathrm{ma}^{-1}$ (B2).

Sediment sliding parameter variation experiments (S1, $\mathrm{S} 2, \mathrm{~S} 3): C_{\mathrm{S}}=100 \mathrm{a}^{-1}(\mathrm{~S} 1), C_{\mathrm{S}}=200 \mathrm{a}^{-1}(\mathrm{~S} 2), C_{\mathrm{S}}=$ $1000 \mathrm{a}^{-1}(\mathrm{~S} 3)$.

\section{OVERVIEW OF ISMIP-HEINO RESULTS}

The results of the ISMIP-HEINO experiment are outlined in detail by Calov and others (2010). In total, nine models participated in the benchmark, eight of which were based on the shallow-ice approximation (SIA) (Hutter, 1983; Morland, 1984) while one represented a combination of the SIA and shallow-shelf approximation (SSA) approach (Morland, 1987; MacAyeal, 1989). Each participating model exhibits oscillations for at least one model set-up of the total number of eight introduced simulations. These findings therefore support the idea that the HEs are caused by a mechanism involving an intrinsic thermomechanical instability. All models display an enhanced tendency to oscillate when the surface temperature and accumulation rate are decreased. However, a more detailed inspection of the results reveals significant differences in the behavior of the models. While two models (' $b$ ' and ' $d$ ') oscillate for all eight simulations, model ' $h$ ' does so for only one experiment; the response of the other models lies between these two limits. The HEINO experiments also display a satisfactory agreement with respect to reproducing the HE-like oscillations at periods from 5 to $15 \mathrm{ka}$, which is in relatively good agreement 
with the geological evidence (Heinrich, 1988). However, the monitored output quantities, i.e. the melt fraction and ice thickness averaged over the sedimentary basin, when they are plotted as functions of time, differ significantly from model to model in terms of their shape and the precise timing of the oscillations (if they occur), and, in addition, in the mean value. The Fourier amplitude spectra used to characterize the frequency content of signals show a rather poor agreement in shape, number and position of significant frequency peaks. These differences are puzzling in view of the overall similarity of the applied numerical approaches. As the models (except for model ' $h$ ') are all of the SIA type, much better consistency and agreement between the results should be expected.

To better quantify the differences in the results, we first introduce a novel spectral tool based on wavelet analysis. The reason for wavelet analysis rather than Fourier analysis is that for the ice-thickness time series, if they oscillate (mainly in experiments ST, T1, B1, S3), the oscillations are not precisely periodic since the lag between two subsequent oscillations appears to be a random quantity. For such a signal, the Fourier spectrum becomes distorted even for a relatively elementary quasi-periodic signal, as a consequence of the global support of the Fourier basis functions (see Appendix). To obtain a better insight into the principal periods present in a quasi-periodic signal, time-localized basis functions are needed. We develop a focused global wavelet spectrum (FGWS), which is derived from the traditional continuous wavelet spectrum (CWS) (see Appendix for details). The FGWS makes use of the information redundancy of the CWS, allowing its modification without affecting the reconstructed timedomain signal. Our modification is designed to give a better spectral resolution than the CWS for a certain class of quasiperiodic signals, having the same basic characteristics as the investigated ISMIP-HEINO ice-thickness output signal.

We choose a particular mother wavelet function (see Appendix) such that there is a correspondence between the scales of the wavelet spectra and the periods in the Fourier amplitude spectrum. The FGWS can then be compared with the Fourier amplitude spectrum. Figure 2 compares the FGWS and the normalized Fourier amplitude spectrum, truncated at the period $T=25 \mathrm{ka}$, for the original ISMIP-HEINO average ice-thickness time series over the sedimentary basin for experiment ST. The time-series data have been kindly provided by R. Calov and other ISMIP-HEINO participants (http://www.pik-potsdam.de/calov/heino_data.html).

We can see that the FGWS are more localized than the Fourier amplitude spectra and provide a better insight into the principal periods contained in the signals. The FGWS also shows large differences between the models. Despite distinct numbers of spectral peaks present in the FGWS, the amplitudes of these peaks differ significantly, and their positions vary between 5 and $20 \mathrm{ka}$.

\section{DESCRIPTION AND VALIDATION OF THE NOVEL 3-D THERMOMECHANICAL ICE-SHEET MODEL}

This study uses a novel numerical ice-sheet model, JOSH (JOint Shallow-ice/Higher-order model), which combines the traditional SIA with a higher-order approach based on the SIA-I algorithm developed by Souček and Martinec (2008). This algorithm computes the SIA in the first step and then iteratively improves the solution. The iterations are based


Fig. 2. The normalized amplitude Fourier spectrum (left) and the FGWS (right), truncated at a period of $25 \mathrm{ka}$ for the participating models $\mathrm{a}-\mathrm{i}$ in the ST ISMIP-HEINO experiment. 
Table 2. EISMINT experiment A, B, C, D, G results. $V$ : glaciated volume; $A$ : glaciated area; $f$ : melt fraction at the glacier bed; $h$ : icedivide thickness; $T$ : basal temperature below the ice divide; $\Delta_{X-Y}$ : change of a quantity between experiments $X$ and $Y$. Two sets of results are displayed for the JOSH model: the SIA simulations and the $\mathrm{HO}$ simulations by the SIA-I algorithm. The EISMINT averages and ranges for the investigated quantities are reprinted for comparison from Payne and others (2000)

\begin{tabular}{|c|c|c|c|c|c|}
\hline & \multirow{2}{*}{ Quantity } & \multicolumn{2}{|c|}{ JOSH } & \multicolumn{2}{|c|}{ EISMINT } \\
\hline & & SIA & $\mathrm{HO}_{(\mathrm{SIA}-\mathrm{l})}$ & mean & range \\
\hline \multirow{5}{*}{ A } & $V\left(10^{6} \mathrm{~km}^{3}\right)$ & 2.072 & 2.063 & 2.128 & 0.145 \\
\hline & $A\left(10^{6} \mathrm{~km}^{2}\right)$ & 1.031 & 1.031 & 1.034 & 0.086 \\
\hline & $f$ & 0.577 & 0.616 & 0.718 & 0.290 \\
\hline & $h(\mathrm{~m})$ & 3709.692 & 3671.180 & 3688.342 & 96.740 \\
\hline & $T(\mathrm{~K})$ & 254.534 & 256.640 & 255.605 & 2.929 \\
\hline \multirow{4}{*}{ B } & $\Delta V_{\mathrm{B}-\mathrm{A}}(\%)$ & -2.957 & -2.813 & -2.589 & 1.002 \\
\hline & $\Delta f_{\mathrm{B}-\mathrm{A}}(\%)$ & 12.129 & 10.915 & 11.836 & 18.669 \\
\hline & $\Delta h_{\mathrm{B}-\mathrm{A}}(\%)$ & -5.460 & -5.374 & -4.927 & 1.316 \\
\hline & $\Delta T_{\mathrm{B}-\mathrm{A}}(\mathrm{K})$ & 4.586 & 4.428 & 4.623 & 0.518 \\
\hline \multirow{5}{*}{ C } & $\Delta V_{\mathrm{C}-\mathrm{A}}(\%)$ & -27.892 & -28.073 & -28.505 & 1.204 \\
\hline & $\Delta A_{\mathrm{C}-\mathrm{A}}(\%)$ & -20.376 & -20.376 & -19.515 & 3.554 \\
\hline & $\Delta f_{\mathrm{C}-\mathrm{A}}(\%)$ & -22.088 & -23.837 & -27.806 & 31.371 \\
\hline & $\Delta h_{\mathrm{C}-\mathrm{A}}(\%)$ & -12.683 & -12.807 & -12.928 & 1.501 \\
\hline & $\Delta T_{\mathrm{C}-\mathrm{A}}(\mathrm{K})$ & 3.678 & 3.964 & 3.707 & 0.615 \\
\hline \multirow{5}{*}{ D } & $\Delta V_{\mathrm{D}-\mathrm{A}}(\%)$ & -11.942 & -11.949 & -12.085 & 1.236 \\
\hline & $\Delta A_{\mathrm{D}-\mathrm{A}}(\%)$ & -10.188 & -10.188 & -9.489 & 3.260 \\
\hline & $\Delta f_{\mathrm{D}-\mathrm{A}}(\%)$ & -1.823 & -2.734 & -1.613 & 5.745 \\
\hline & $\Delta h_{\mathrm{D}-\mathrm{A}}(\%)$ & -2.049 & -2.052 & -2.181 & 0.532 \\
\hline & $\Delta T_{\mathrm{D}-\mathrm{A}}(\mathrm{K})$ & -0.180 & -0.222 & -0.188 & 0.060 \\
\hline \multirow{5}{*}{ G } & $V\left(10^{6} \mathrm{~km}^{3}\right)$ & 1.498 & 1.502 & 1.589 & 0.702 \\
\hline & $A\left(10^{6} \mathrm{~km}^{2}\right)$ & 1.031 & 1.031 & 1.032 & 0.071 \\
\hline & $f$ & 0.303 & 0.272 & 0.352 & 0.530 \\
\hline & $h(\mathrm{~m})$ & 2209.206 & 2211.509 & 2365.206 & 1468.880 \\
\hline & $T(\mathrm{~K})$ & 248.177 & 248.926 & 249.134 & 7.681 \\
\hline
\end{tabular}

on a procedure analogous to the SIA, but applied only to deviations of the approximate solution from the exact fullStokes solution. Its ability to capture higher-order effects by including the longitudinal stresses has been demonstrated in the ISMIP-HOM experiment (Pattyn and others, 2008; model oso1). We implemented the SIA-I algorithm into an evolutionary three-dimensional (3-D) thermomechanical ice-sheet model. A finite-difference technique is applied for discretizing the governing equations, i.e. the SIA-I linear momentum and rheology equations, the kinematic equation for a free glacier surface and the heat-transport equation. The SIA-I algorithm uses a simple Arakawa A grid (Arakawa, 1977) for discretization, i.e. each node contains all the field variables. Details of the numerics are given by Souček (2010).

To verify the capability of JOSH to perform thermomechanically coupled ice-sheet simulations, we benchmark it following the EISMINT experiments (A, B, C, D, G) from the exercise 'Effect of thermomechanical coupling' (Payne and others, 2000). These experiments compare the steady-state geometry and the thermodynamic state of an axisymmetric ice sheet whose evolution is simulated from initially icefree conditions under a prescribed steady climatic forcing. In addition, the effect of variations in climate forcing on the resultant steady state is investigated. Table 2 shows our results for both the SIA and the $\mathrm{HO}$ modes, together with the published EISMINT results. For the HO simulations, we used 20 SIA-I iterations with projection parameters $\Theta_{1}=$ 0.2 and $\Theta_{2}=0.2$ (Souček and Martinec, 2008). Table 2 shows that JOSH is capable of reproducing the EISMINT results with sufficient accuracy. It also provides us with a crude estimate of the effect of $\mathrm{HO}$ dynamics for such a type of experiment. The differences between our $\mathrm{SI}$ and $\mathrm{HO}$ simulations by JOSH confirm the findings of a different $\mathrm{HO}$ model by Pattyn (2003). Employing the HO approximation results in a slightly thinner ice sheet $(\sim 40 \mathrm{~m}$ difference at the ice divide for experiment A) and a slightly warmer base ( $\sim 2 \mathrm{~K}$ at the base below the ice divide for experiment $\mathrm{A}$ ). Note that the differences between the $\mathrm{HO}$ and the SI results are approximately of the same order as the range among the published SIA-based EISMINT models.

\section{ISMIP-HEINO RESULTS FOR THE JOSH MODEL SI mode}

We first recomputed the ISMIP-HEINO experiments in the SI mode by performing only the first iteration of the SIAI algorithm. In Figure 3, the time series of averaged ice thickness over the sedimentary basin for the three types of experiments (T1, T2), (B1, B2), (S1, S2, S3) are shown and compared with the reference simulation, ST. We plot the results for the time interval 50-200 ka of simulation time, during which the ice sheet is already fully developed. In Figure 4, the Fourier amplitude spectra truncated at the period of $T=25 \mathrm{ka}$ and normalized to unity over this interval are shown, while in Figure 5 we present the corresponding FGWS.

We observe that only few oscillations are generated by JOSH for the reference ST simulation, but significant oscillations occur in the T1 experiment (a colder surface), the B1 experiment (a reduced accumulation rate) and the S3 experiment (fast sliding over the sedimentary basin). This is in good qualitative agreement with results of the ISMIP-HEINO experiment, as all three conditions favor repeated refreezing of the glacier base after a period of rapid sliding. Note that the dominant period in the FGWS for all significantly oscillating signals is $\sim 10 \mathrm{ka}$.

\section{HO mode (SIA-I)}

The T1 experiment, which exhibits clear oscillations, is taken as a reference simulation for investigating the effect of the $\mathrm{HO}$ approximation in the ice-flow equations. The $\mathrm{HO}$ approximation is implemented by the SIA-I algorithm (Souček and Martinec, 2008) (using 20 SIA-I iterations and projection parameters $\Theta_{1}=0.2, \Theta_{2}=0.2$ ). The SIA-I algorithm converges to a solution adjusting the rheology equations exactly and linear momentum equations with an error of $\mathrm{O}\left(\varepsilon^{2}\right)$ ( $\varepsilon$ being the height/length aspect ratio of the ice sheet). The algorithm is presented in detail by Souček and Martinec (2008), and its convergence and accuracy are discussed by Souček (2010). The SIA-I algorithm solves only the linear momentum and rheology equations. The heattransport equation is solved in the SI approximation (e.g. Greve, 1997) with the $\mathrm{HO}$ advection velocities delivered by the SIA-I. Two different $\mathrm{HO}$ simulations are performed. In the first simulation, denoted ' $\mathrm{HO}-1$ ', the sliding law is kept in the SI form, i.e. $\boldsymbol{\tau}_{\mathrm{b}}$ in Equations (3) and (4) is taken as

$$
\boldsymbol{\tau}_{\mathrm{b}}=\rho g H \nabla_{\mathrm{h}} H,
$$



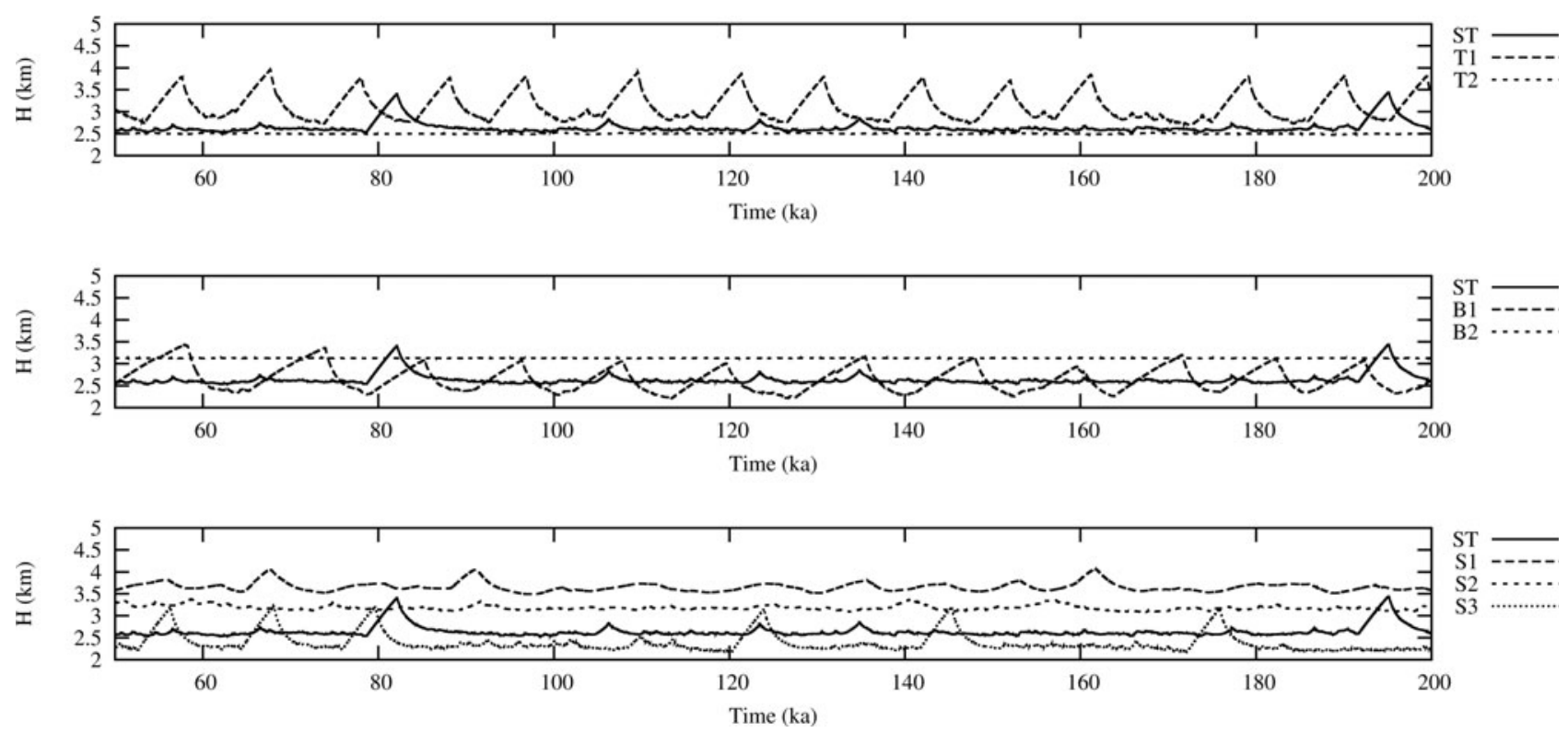

Fig. 3. The average ice thickness, $H$, over the sedimentary basin for experiments $\mathrm{ST}, \mathrm{T} 1, \mathrm{~T} 2$ (top panel), ST, B1, B2 (middle panel) and ST, $\mathrm{S} 1, \mathrm{~S} 2$, S3 (bottom panel), for the ISMIP-HEINO experiments with the JOSH model in SI mode.
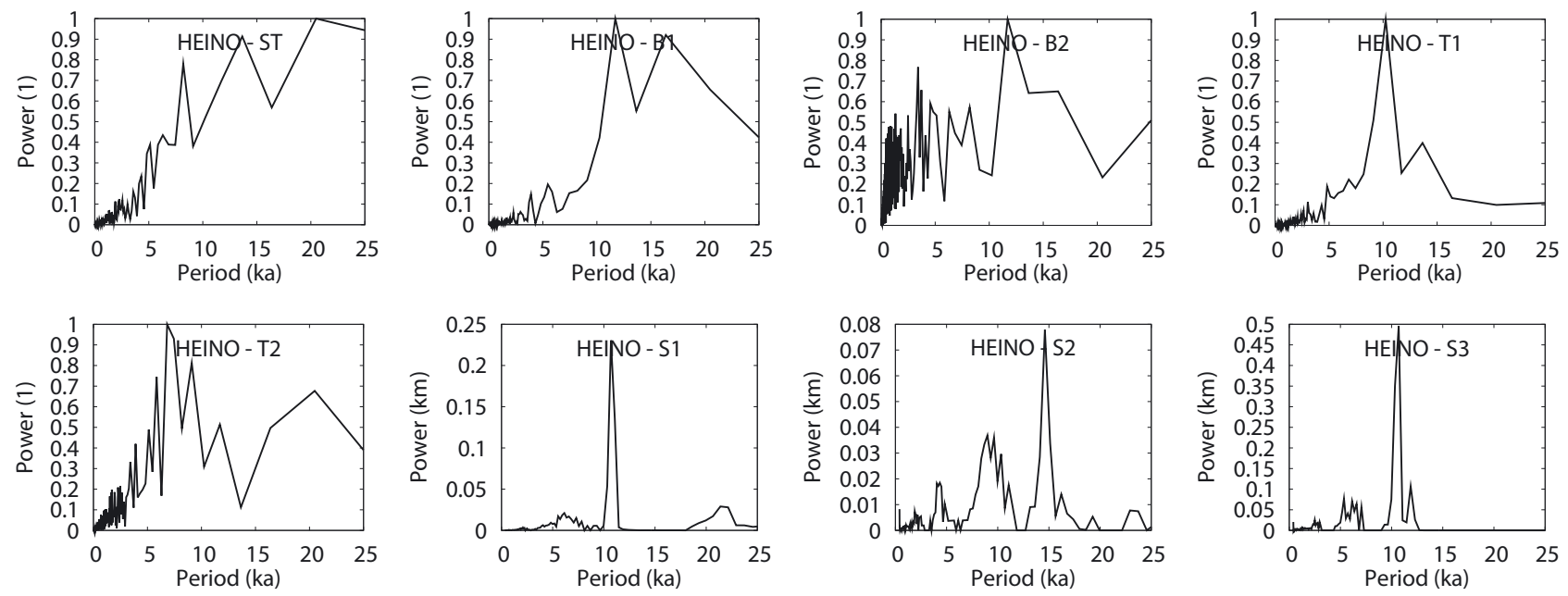

Fig. 4. The normalized Fourier amplitude spectra of the time series of Figure 3 truncated at $25 \mathrm{ka}$.
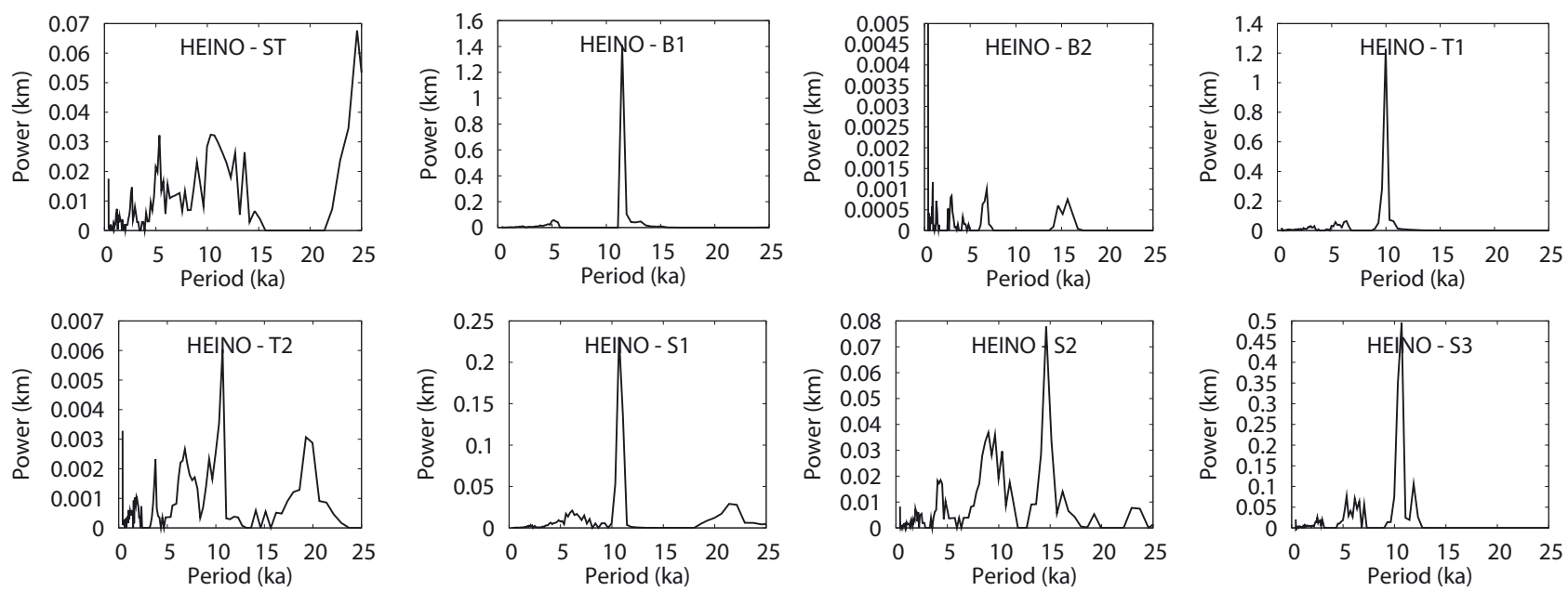

Fig. 5. Same as Figure 4, but for the FGWS. 


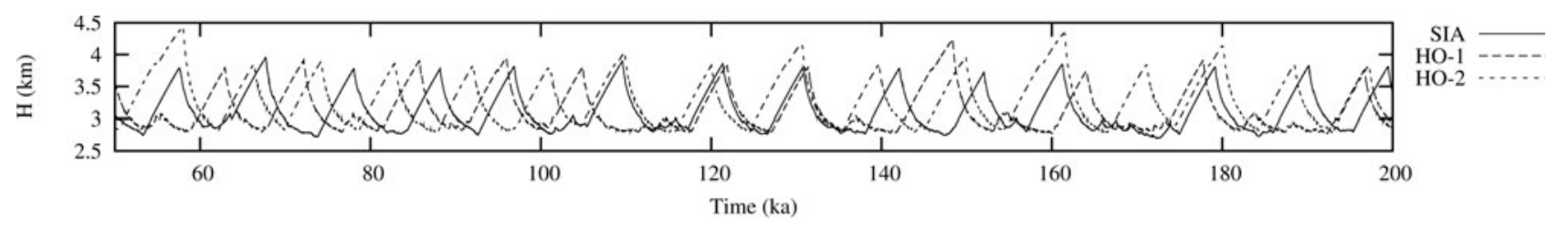

Fig. 6. The average ice thickness, $H$, over the sedimentary area for the $\mathrm{T} 1$ experiment, performed in the SI mode (SIA), higher-order mode with the SIA sliding law (HO-1) and fully $\mathrm{HO}$ mode (HO-2).

where $\nabla_{\mathrm{h}} H$ is the horizontal gradient of the ice thickness, $H$. In the second simulation, denoted 'HO-2', a $\mathrm{HO}$ approximation of the basal traction, $\boldsymbol{\tau}_{\mathrm{b}}$, obtained by the SIA-I solution is employed in the sliding law, i.e. we take $\boldsymbol{\tau}_{\mathrm{b}}=-\left(t_{x z}^{\mathrm{b}}, t_{y z}^{\mathrm{b}}, 0\right)$, where $t_{x z}^{\mathrm{b}}$ and $t_{y z}^{\mathrm{b}}$ are the components of the $\mathrm{HO}$ Cauchy stress tensor at the glacier base.

Both $\mathrm{HO}$ simulations are performed for the $\mathrm{T} 1$ experiment set-up. The simulations are initiated from ice-free conditions and run for $200 \mathrm{ka}$ with a time-step of 0.25 years. The simulated time series of average ice thickness and the reference $\mathrm{T} 1 \mathrm{SIA}$ solution above the sedimentary basin are shown in Figure 6. In Figure 7 the Fourier amplitude spectra and FGWS for the three simulations (SIA, HO-1, $\mathrm{HO}-2$ ) are shown. While already visible in the time series, the spectra confirm that (1) the principal periods of $\mathrm{HO}-1, \mathrm{HO}-2$ and the SIA oscillations coincide very well, with a tiny shift of the $\mathrm{HO}-1$ spectrum to larger periods compared with the HO-2 spectrum; and (2) the amplitude and number of oscillations relative to the SIA run is slightly decreased in the $\mathrm{HO}-1$ experiment and increased in the $\mathrm{HO}-2$ experiment, resulting in the observed differences in amplitudes of the FGWS.

\section{ASSESSING THE ROBUSTNESS OF THE ISMIP-HEINO RESULTS}

\section{Sensitivity study I: effect of surface temperature noise}

To assess the robustness of the results from the previous section, we perturb the surface temperature field, $T_{\text {surf }}$, by spatially non-correlated normal Gaussian noise with the distribution $N(0,1)$ and amplitude $\Delta T=0.01 \mathrm{~K}$. The $\mathrm{T} 1$ experiment is performed for a number of the realizations of the noise, $\Delta T \cdot N(0,1)$, where again the time series and corresponding Fourier amplitude spectra and FGWS for the average ice thickness over the sedimentary basin are monitored. The model response to relatively low levels of noise in the surface temperature, shown in Figure 8 for several time series, is surprisingly strong. We can see that the curves become quickly out of phase after initialization, typically within the characteristic period of the oscillations, which is $\sim 10 \mathrm{ka}$ for this experiment. Despite the similarity in amplitude and shape of the oscillations, the time series appears chaotic, due to a randomness in the time lag between subsequent oscillations. As a result, the Fourier amplitude spectra, shown in Figure 9, are distorted and poorly resolved. The FGWS, in contrast, are better localized with less distortion. Nevertheless, the dominant period of the FGWS is resolved with an uncertainty of $\pm 2 \mathrm{ka}$. Since it is unlikely that the applied temperature perturbations should have a considerable impact on the ice-sheet dynamics, the resulting chaotic behavior is to be interpreted as a deficiency in the numerical model, and the value of $\pm 2 \mathrm{ka}$ is to be understood as the uncertainty of the FGWS for the ISMIPHEINO experiments.

In view of these results, the differences between the $\mathrm{HO}$ and the $\mathrm{SI}$ approximations investigated in the previous paragraph are within the uncertainty of the FGWS amplitude and period, and therefore the effect of $\mathrm{HO}$ dynamics on the HE oscillations is negligible. Also, the model sensitivity to surface temperature variations suggests a possible interpretation of the differences among the ISMIPHEINO results. We suggest that these differences are caused by the differences in the modelled temperature fields. The following experiment supports this hypothesis.
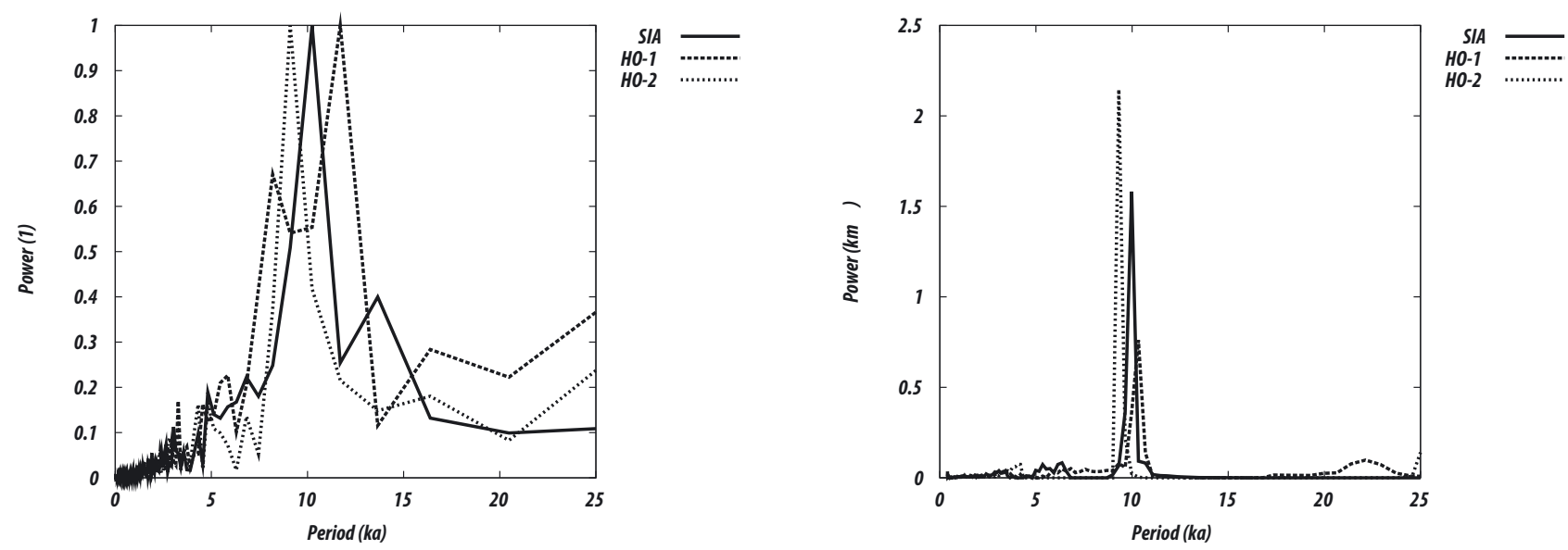

Fig. 7. The Fourier amplitude spectra (left) and FGWS (right) for experiment T1, performed in the SI mode (SIA), higher-order mode with the SIA sliding law (HO-1) and fully $\mathrm{HO}$ mode (HO-2). All spectra are truncated at a period of $25 \mathrm{ka}$. 


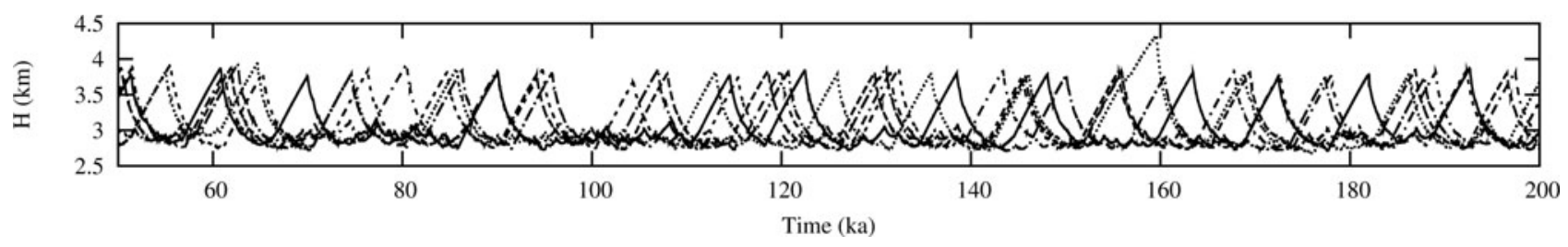

Fig. 8. The average ice thickness, $H$, over the sedimentary basin for the surface temperature noise perturbations experiment.

\section{Sensitivity study II: effect of uncertainty in the modelled temperature field}

In the previous subsection we studied the effect of noise in the surface temperature; we now investigate the JOSH model's response to surface temperature variations with amplitudes corresponding to the uncertainties in the modelled basal temperature fields. This value is not known precisely, but may be estimated from the results of the EISMINT benchmark experiment, exercise 'Effect of thermomechanical coupling' (Payne and others, 2000). We inspect EISMINT experiments $\mathrm{G}$ and $\mathrm{H}$, which include the physical phenomena influencing the ISMIP-HEINO experiments, i.e. the dynamics of an ice sheet of continental dimension with a temperature-dependent ice rheology and basal sliding either decoupled (experiment G) or coupled (experiment $\mathrm{H}$ ) with the basal temperatures. The results (Payne and others, 2000, tables 8 and 9) show (after rejecting an obvious outlier model ' $U$ ') that there is good agreement in the modelled topography and ice thickness. However, the divide basal temperatures and the basal melt fractions differ significantly. For experiment $\mathrm{G}$, the ice-divide basal temperature varies between 247.700 and $249.482 \mathrm{~K}$ and the melt fraction between 0.250 and 0.391 ; for experiment $\mathrm{H}$, the divide basal temperature is between 253.737 and $256.714 \mathrm{~K}$ and the melt fraction between 0.351 and 0.622. Based on these EISMINT discrepancies, we vary the surface temperature uniformly from $\Delta T=-3$ to $+3 \mathrm{~K}$ and investigate the influence in the ISMIP-HEINO experiment ST in the SI mode. The time series in Figure 10 reveal a considerable effect resulting from the $\pm 3 \mathrm{~K}$ temperature variations. As expected, the occurrence of HE-like oscillations is most frequent for the coldest $(\Delta T=-3 \mathrm{~K})$ scenario. With increasing temperature the shape of the 'shark-tooth' oscillations does not change, but the time-averaged lag between neighboring oscillations increases until a threshold value of $\Delta T=+1.2 \mathrm{~K}$, above which oscillations do not occur.

In Figure 11 the Fourier amplitude spectra and the FGWS are shown for a series of simulations with gradually increasing $\Delta T$. It is not possible to draw any conclusions from the Fourier amplitude spectra, but the FGWS show a tendency of gradually decreasing amplitudes and peak values shifting to longer periods with increasing temperature. This spectral behavior reflects the elongation of the gaps between subsequent oscillations, as observed in the time series in Figure 10. This simulation suggests that small deviations in basal temperature modelling, as deduced from the results of the EISMINT experiment, may significantly affect the occurrence of Heinrich oscillations in the numerical model.

In Figure 12, the FGWS for the published ISMIP-HEINO results (models $\mathrm{a}-\mathrm{i}$ ) are shown. The figure confirms a large variability in the results, both in the FGWS amplitudes and the dominant periods, which typically range from 5 to $15 \mathrm{ka}$. As shown in Figure 5, our numerical model has a dominant period of $\sim 10 \mathrm{ka}$ for all significantly oscillating experiments (T1, B1, S3).

These results may partially explain the variance among the ISMIP-HEINO dominant periods in the FGWS. If the model temperature rises, the average length of gaps between subsequent oscillations increases, and the FGWS peak is shifted to larger periods. However, by this argument, we cannot explain the converse process: a shift of the dominant peak towards shorter periods, such as $5 \mathrm{ka}$, clearly visible in Figure 12 for several ISMIP-HEINO models. In addition, by inspecting the time series (http://www.pikpotsdam.de/calov/heino.html), we find that some models
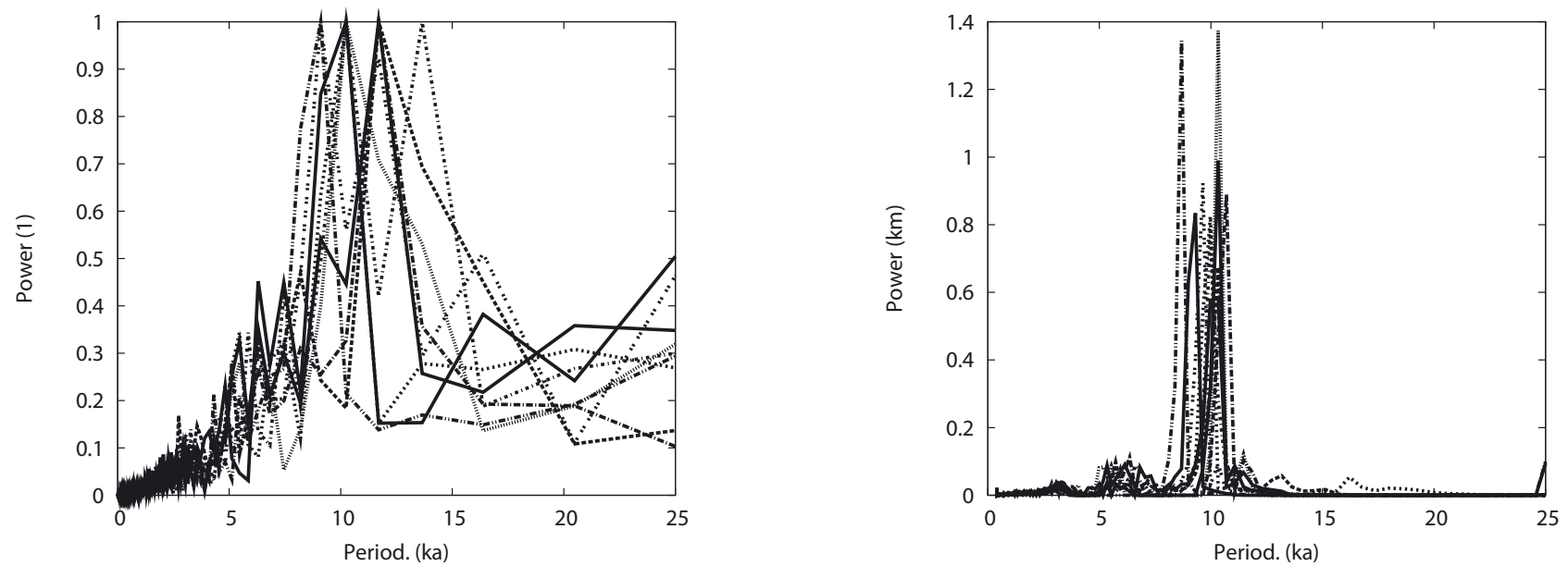

Fig. 9. The Fourier amplitude spectra (left) and FGWS (right) for the time series in Figure 8, truncated at a period of $25 \mathrm{ka}$. 

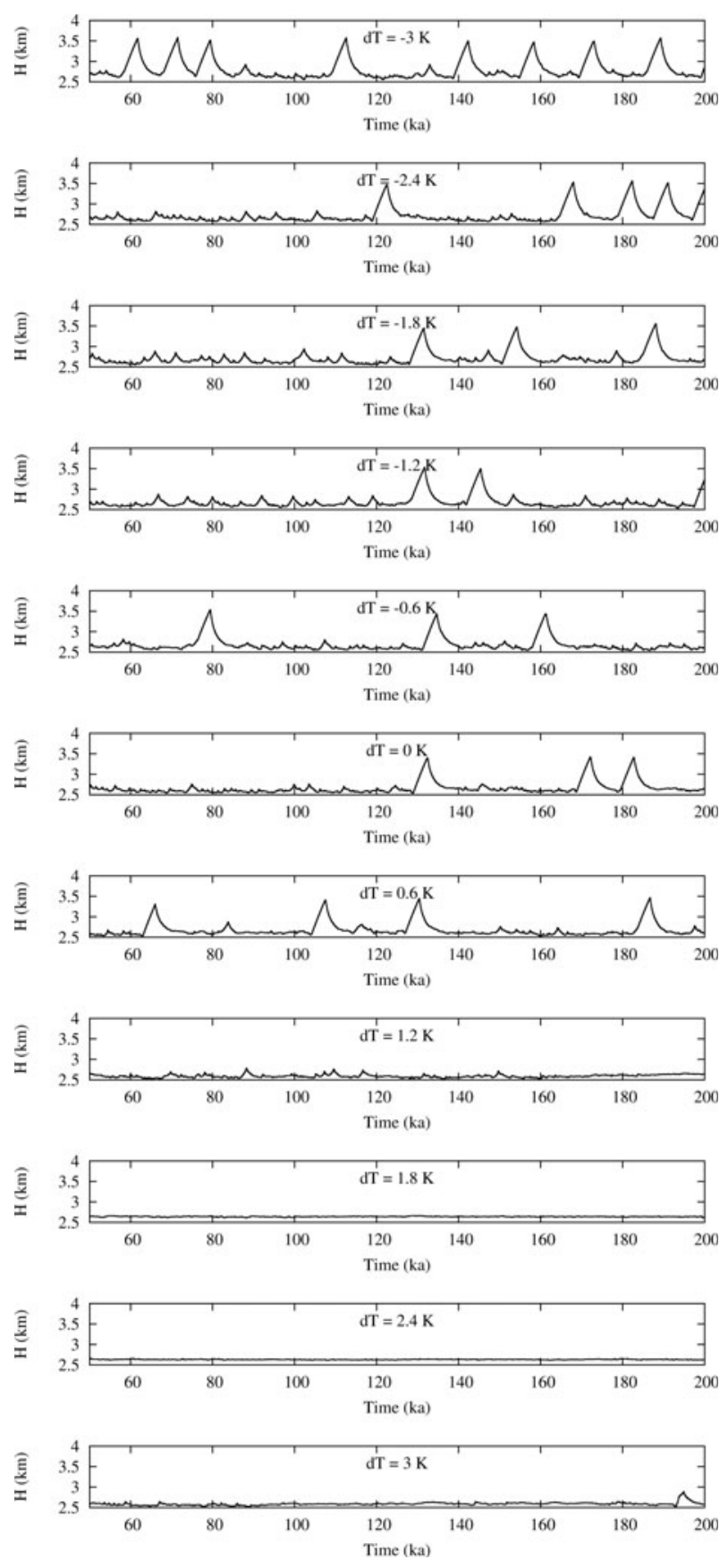

Fig. 10. Time series of the average ice thickness over the sedimentary area. ISMIP-HEINO ST set-up is modified by uniform surface temperature variations ranging from $-3 \mathrm{~K}$ (top) to $+3 \mathrm{~K}$ (bottom).
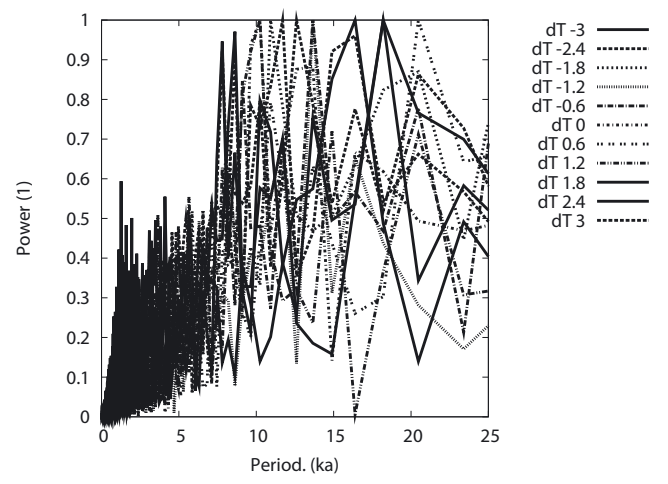

exhibit 'shark-tooth'-like oscillations, while others have a more symmetric and rounded shape. We observe, however, that for different temperatures the shape of the oscillations does not change significantly, only the gaps between them. A possible explanation of both these issues is given by the next experiment.

\section{Sensitivity study III: effect of numerical implementation of the basal sliding condition}

The previous two experiments indicate the large sensitivity of the appearance of the HE oscillations to surface temperature variations. This may be caused by a combination of two effects: (1) the local nature of the sliding condition and (2) a positive feedback of the frictional heat production on basal temperatures once sliding starts. As expected, such a localized coupled mechanism is extremely sensitive to its numerical implementation. In table 3 of Calov and others (2010) a variety of numerical schemes adopted for discretizing the heat-transport equation (Arakawa A, C, $\mathrm{ACH}, \mathrm{ABH}$ grids) are presented. Since temperatures are computed at different nodes to the velocities (except for the A-grid scheme), an interpolation of temperatures at the velocity nodes must be performed when evaluating the stick-slip temperature condition, $T=T_{M}$, where $T_{M}$ is the melting temperature. We compare the performance of two interpolation schemes.

As mentioned above, the SIA-I algorithm that the JOSH numerical model employs is the Arakawa A grid in the momentum and rheology equations (velocity and stress tensor are computed and stored at the same nodes). The present version of JOSH uses the same grid for discretizing the heat-transport equation. In all the previous experiments, when the basal sliding condition is evaluated, for the sake of better stability, the basal temperature at the node is computed as a weighted average of temperatures of surrounding nodes

$$
\bar{T}_{i, j}=\frac{T_{i, j}}{2}+\frac{T_{i+1, j}+T_{i-1, j}+T_{i, j+1}+T_{i, j-1}}{8} .
$$

The sliding is thus activated when

$$
\bar{T}_{i, j} \geq T_{\mathrm{Mi}, j}
$$

We denote this as scheme A. Scheme B does not use any temperature averaging, i.e. sliding is activated when

$$
T_{i, j} \geq T_{M i, j}
$$


Figures 13 and 14 show the time series and corresponding FGWS for the averaged ice thickness over the sedimentary basin for schemes $A$ and $B$, respectively.

The oscillations for scheme A, when they occur, are 'sharktooth'-like, while those for scheme B are more symmetric and rounded and of smaller amplitudes (with the exception of experiment B2). The average ice thickness for scheme B over the sedimentary basin is significantly larger than for scheme A. By inspecting the FGWS, we observe that the spectral peaks for scheme B are systematically shifted towards shorter periods compared with scheme A. Dominant oscillations occur at $5 \mathrm{ka}$ for scheme $B$, while they are $\sim 10 \mathrm{ka}$ for scheme A.

\section{DISCUSSION AND CONCLUSIONS}

We have performed all the ISMIP-HEINO simulations with a novel 3-D thermomechanically coupled numerical icesheet model based on the SIA-I algorithm, which allows us to incorporate a $\mathrm{HO}$ approximation of the rheology and linear momentum equations. To assess the effects of the $\mathrm{HO}$ dynamics, we first carried out a series of simulations for the ISMIP-HEINO T1 experimental set-up, where the surface temperature is varied by a Gaussian spatially noncorrelated noise with a small amplitude $(\sim 0.01 \mathrm{~K})$. The icesheet model responds to this minor temperature perturbation such that the onset of the HEs is random, while their shape and amplitude remains unchanged. We conclude that this is caused by the local character of the sliding condition, i.e. the temperature condition at a particular basal gridpoint defines whether the ice-sheet bed is frozen or sliding at this point. This locality and the positive feedback in the sliding activation by frictional heat produced by sliding leads to the extreme sensitivity of the basal sliding activation to temperature variations. This causes random behavior of the results with respect to temperature variations. This explanation is supported by an observed break-up of spatial symmetry (Calov and others, 2010), where the model outputs exhibit a spatial non-symmetry with respect to the symmetry axis of the model set-up. For a chaotic dynamical system, rounding errors of the order of machine precision, which do not follow any symmetry, will suffice to cause a symmetry break-up of the long-term model behavior.

We have shown that the Fourier amplitude spectrum is strongly affected by the random character of the lags between subsequent $\mathrm{HE}$ oscillations. We therefore developed a FGWS, which is more robust to random behavior within a signal than Fourier amplitude spectra.

We have recomputed ISMIP-HEINO experiment T1 with $\mathrm{SI}$ and $\mathrm{HO}$ approximations of the linear momentum and rheology equations. For the $\mathrm{HO}$ simulation, the sliding law was either approximated by the SI approximation, or used in the $\mathrm{HO}$ form. By comparing the FGWS for the SI and the two $\mathrm{HO}$ simulations, we conclude that the differences between all approaches are within an uncertainty limit due to the chaotic character of the oscillations. Therefore, employing the $\mathrm{HO}$ ice dynamics does not affect the occurrence or the character of the 'Heinrich event' instabilities. All the SI simulations produce significant oscillations in experiments T1, B1 and S3, which are manifested in the FGWS by welllocalized peaks at a period approximately corresponding to $10 \mathrm{ka}$.

We have computed the FGWS for the published ISMIP$\mathrm{HEINO}$ results and suggest an explanation for the differences
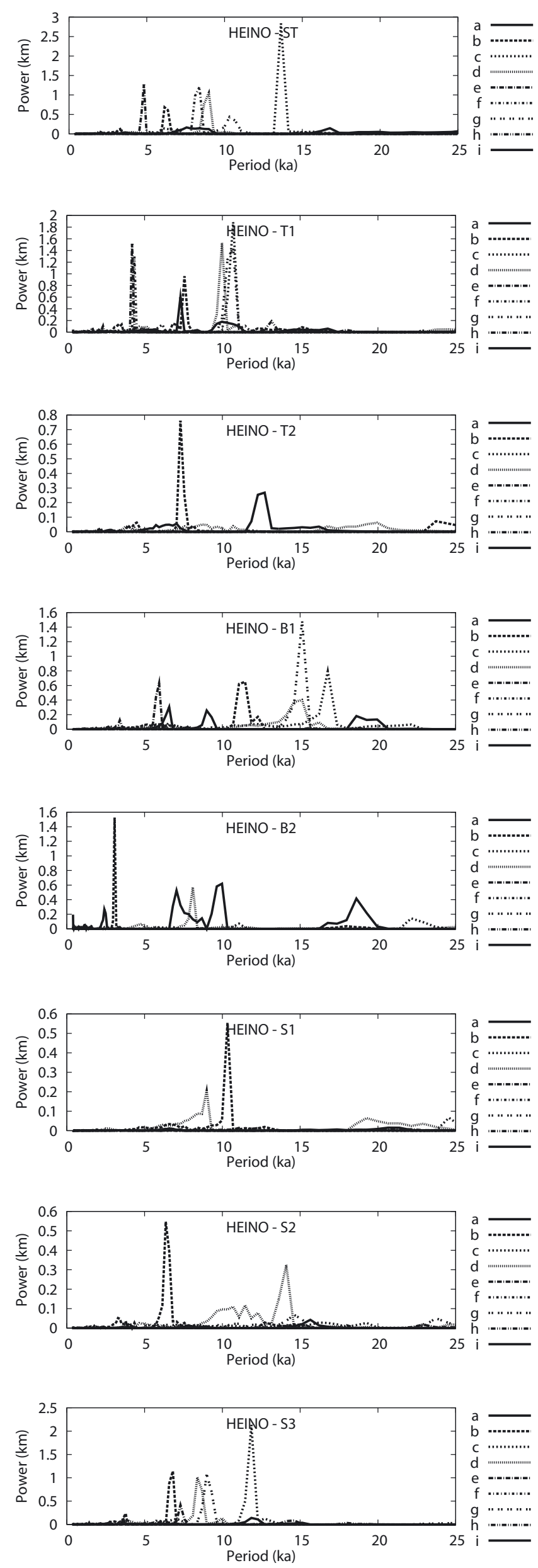

Fig. 12. The FGWS for all ISMIP-HEINO experiments for models a-i. 

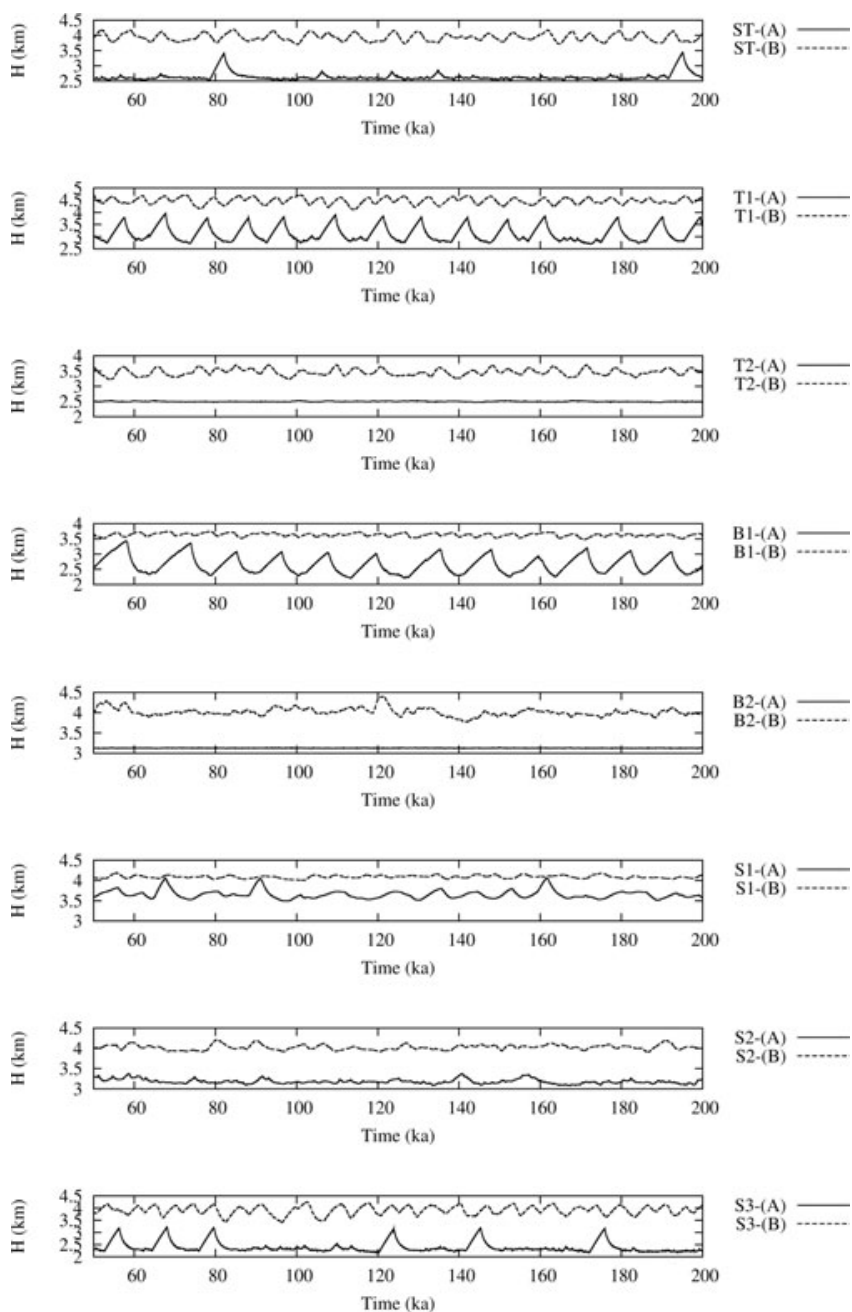

Fig. 13. Time series of the average ice thickness over the sedimentary basin for two different implementations of the sliding condition. The solid line corresponds to a weighted average of neighboring temperatures (scheme A), and the dashed line corresponds to the case where only a local temperature is compared with the local pressure-melting point (scheme B).

in the model responses. These are caused by (1) differences in the simulated temperature fields and (2) the numerical implementation of the basal sliding condition. To estimate the role of the first effect, we performed a temperature sensitivity study with the temperature-field variations estimated from the EISMINT experiment uncertainties. By changing the surface temperatures in the ISMIP-HEINO ST experiment, we observed an increase in the lags between subsequent $\mathrm{HE}$ oscillations with increasing temperature. For $\Delta T \geq 1.2 \mathrm{~K}$ the oscillations vanished completely. The amplitude and the shape of the oscillations are, however, unaffected by the temperature changes. The FGWS shows a shift of the dominant spectral peak to larger periods with gradually decreasing amplitude. This is caused by the enlargement of the gaps between produced HEs.

Temperature variations solely, however, cannot explain the differences in the shape of the oscillations in the time series of average ice thickness. Neither can they explain why some models exhibit frequency peaks at significantly shorter periods $(\sim 5 \mathrm{ka})$ in the FGWS, as found by processing the ISMIP-HEINO results.
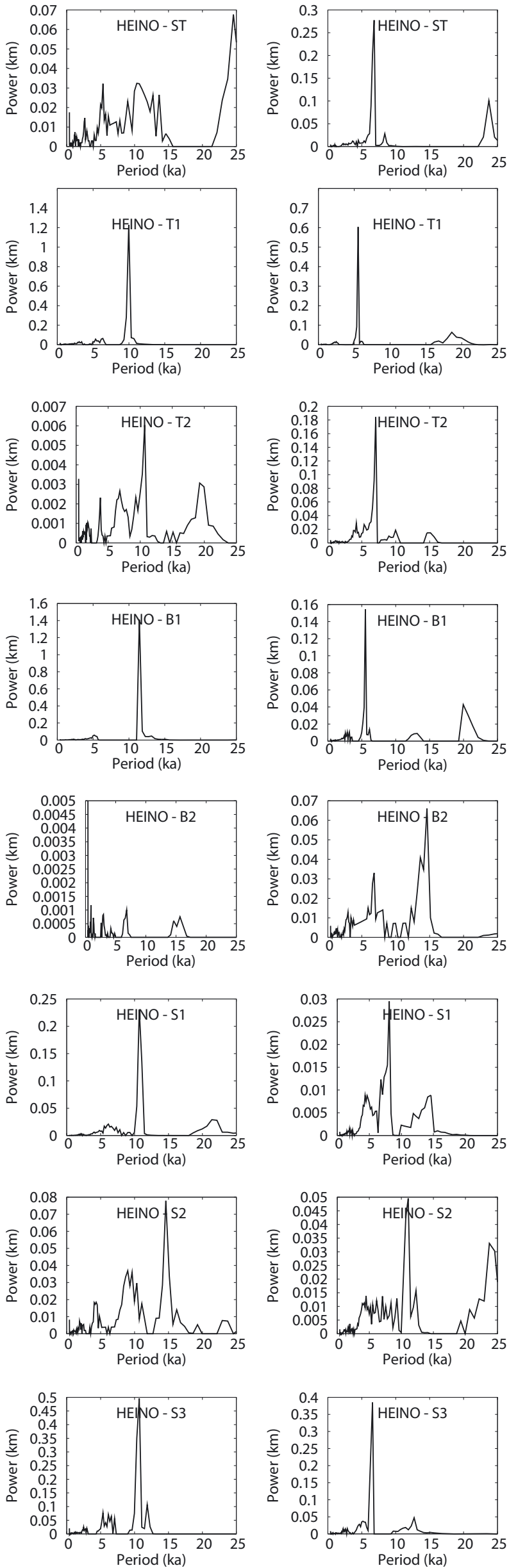

Fig. 14. FGWS of the time series shown in Figure 13 scheme A (left) and scheme B (right). 
In the next stage, we therefore focused on the role of numerical implementation of the sliding condition at the glacier base. We implemented two schemes. First, the basal temperature when evaluating the sliding condition is computed as a weighted average of the temperatures at neighboring nodes in order to mimic the staggered-grid approach and to stabilize numerical computations. Second, the basal temperature when evaluating the sliding condition is taken as the local temperature at a given basal node. The two schemes result in significantly different model outputs: (1) the mean ice thickness over the sedimentary basin is larger for the latter scheme and (2) the shape and the dominant FGWS periods of oscillations are changed. Significant oscillations generated by experiments T1, T2, B1 and S3 are characterized by frequency peak in the FGWS at a period of $5 \mathrm{ka}$ for the latter scheme, which is about half the period resulting from implementing the first basal sliding scheme.

In conclusion, all the performed numerical experiments imply that the traditional sliding condition needs to be revised, especially its numerical implementation into SI models. In its local form, based on evaluating pointwise the temperature sliding criterion, $T \geq T_{\mathrm{M}}$, the local character of the $\mathrm{SI}$ approximation of the linear momentum, rheology and temperature equations, leads inevitably to the occurrence of numerical instabilities and to an extreme sensitivity to the numerical implementation. In view of the discrepancy in simulated basal-temperature and melt-fraction fields, as documented in the EISMINT experiments (Payne and others, 2000), the implementation of surge-type physics in largescale ice-sheet models is rather problematic since the information about the physical instability may be lost in the numerics. It is beyond the scope of this paper to suggest any improvements to the sliding criterion, but we believe that (1) the onset of sliding should be smooth when the temperature approaches the basal melting temperature (a possible regularization by sub-melt sliding has been studied by Greve and others 2006; see also the 'Discussion and conclusion' section of Calov and others, 2010); and (2) the sliding criterion should be spatially delocalized in the sense that it would suppress onset of rapid sliding of a single basal gridpoint (surrounded by 'frozen-bed' gridpoints). Such behavior is both unrealistic and favors numerical instabilities in the model.

\section{ACKNOWLEDGEMENTS}

Z.M. acknowledges support from the Grant Agency of the Czech Republic through grant No. 205/09/0546. We are indebted to T. Kleiner, R. Greve and an anonymous reviewer for helpful remarks and suggestions and to K. Fleming for help with correcting the English.

\section{REFERENCES}

Andrews, J.T. 1998. Abrupt changes (Heinrich events) in late Quaternary North Atlantic marine environments: a history and review of data and concepts. J. Quat. Sci., 13(1), 3-16.

Arakawa, A. and V.R. Lamb. 1977. Computational design of the basic dynamical processes of the UCLA general circulation model. In Chang, J., ed. General circulation models of the atmosphere. New York, Academic Press, 173-265.
Bond, G. and 13 others. 1992. Evidence for massive discharges of icebergs into the North Atlantic Ocean during the last glacial period. Nature, 360(6401), 245-249.

Broecker, W.S. 1994. Massive iceberg discharges as triggers for global climate change. Nature, 372(6505), 421-424.

Calov, R., A. Ganopolski, V. Petoukhov, M. Claussen and R. Greve. 2002. Large-scale instabilities of the Laurentide ice sheet simulated in a fully coupled climate-system model. Geophys. Res. Lett., 29(24), 2216. (10.1029/2002GL016078.)

Calov, R. and 9 others. 2010. Results from the Ice-Sheet Model Intercomparison Project-Heinrich Event INtercOmparison (ISMIP HEINO). J. Glaciol., 56(197), 371-383.

Clarke, G.K.C., S.J. Marshall, C. Hillaire-Marcel, G. Bilodeau and C. Veiga-Pires. 1999. A glaciological perspective on Heinrich events. In Clark, P.U., R.S. Webb and L.D. Keigwin, eds. Mechanisms of global climate change at millennial time scales. Washington, DC, American Geophysical Union, 243-262.

Daubechies, I. 1992. Ten lectures on wavelets. Second edition. Philadelphia, PA, SIAM.

Glen, J.W. 1955. The creep of polycrystalline ice. Proc. R. Soc. London, Ser. A, 228(1175), 519-538.

Greve, R. 1997. A continuum-mechanical formulation for shallow polythermal ice sheets. Philos. Trans. R. Soc. London, Ser. A, 355(1726), 921-974.

Greve, R. and D.R. MacAyeal. 1996. Dynamic/thermodynamic simulations of Laurentide ice-sheet instability. Ann. Glaciol., 23, 328-335.

Greve, R., R. Takahama and R. Calov. 2006. Simulation of largescale ice-sheet surges: the ISMIP HEINO experiments. Polar Meteorol. Glaciol., 20, 1-15.

Heinrich, H. 1988. Origin and consequences of cyclic ice rafting in the northeast Atlantic Ocean during the past 130000 years. Quat. Res., 29(2), 142-152.

Hindmarsh, R.C.A. and E. Le Meur. 2001. Dynamical processes involved in the retreat of marine ice sheets. J. Glaciol., 47(157), 271-282.

Hulbe, C.L., D.R. MacAyeal, G.H. Denton, J. Kleman and T.V. Lowell. 2004. Catastrophic ice shelf breakup as the source of Heinrich event icebergs. Paleoceanography, 19(1), PA1004. (10.1029/2003PA000890.)

Hutter, K. 1983. Theoretical glaciology; material science of ice and the mechanics of glaciers and ice sheets. Dordrecht, etc., D. Reidel Publishing Co./Tokyo, Terra Scientific Publishing Co.

MacAyeal, D.R. 1989. Large-scale ice flow over a viscous basal sediment: theory and application to Ice Stream B, Antarctica. J. Geophys. Res., 94(B4), 4071-4087.

MacAyeal, D.R. 1993. Binge/purge oscillations of the Laurentide ice sheet as a cause of the North Atlantic's Heinrich events. Paleoceanography, 8(6), 775-784.

Meier, M.F. and A. Post. 1987. Fast tidewater glaciers. J. Geophys. Res., 92(B9), 9051-9058.

Morland, L.W. 1984. Thermomechanical balances of ice sheet flows. Geophys. Astrophys. Fluid Dyn., 29(1-4), 237-266.

Morland, L.W. 1987. Unconfined ice-shelf flow. In Van der Veen, C.J. and J. Oerlemans, eds. Dynamics of the West Antarctic ice sheet. Dordrecht, etc., D. Reidel Publishing Co., 99-116.

Pattyn, F. 2003. A new three-dimensional higher-order thermomechanical ice-sheet model: basic sensitivity, ice stream development, and ice flow across subglacial lakes. J. Geophys. Res., 108(B8), 2382. (10.1029/2002JB002329.)

Pattyn, F. and 20 others. 2008. Benchmark experiments for higher-order and full-Stokes ice sheet models (ISMIP-HOM). Cryosphere, 2(2), 95-108.

Payne, A.J. 1995. Limit cycles in the basal thermal regime of ice sheets. J. Geophys. Res., 100(B3), 4249-4263.

Payne, A.J. and 10 others. 2000. Results from the EISMINT model intercomparison: the effects of thermomechanical coupling. J. Glaciol., 46(153), 227-238.

Souček, O. 2010. Numerical modeling of ice sheet dynamics. (PhD thesis, Charles University in Prague.) 
Souček, O. and Z. Martinec. 2008. Iterative improvement of the shallow-ice approximation. J. Glaciol., 54(188), 812-822.

Torrence, C. and G.P. Compo. 1998. A practical guide to wavelet analysis. Bull. Am. Meteorol. Soc., 79, 61-78.

\section{APPENDIX}

\section{Focused global wavelet spectrum (FGWS)}

Sensitivity experiment I shows that if the surface temperature is perturbed by a Gaussian noise of a small amplitude, the model response changes dramatically. While the overall character and amplitudes of the oscillations remain similar, the phases of the oscillations appear to vary randomly. As a result, the simulated time series for average ice thickness quickly become uncorrelated. To analyze such time series by the traditional Fourier spectrum method is useless, due to the global support of the Fourier function basis. Here we develop a spectral tool that is better localized in time and reduces the distortion of the spectrum due to the randomness in the lags between the oscillations.

We employ the continuous wavelet transform (CWT), which satisfies the desired assumption of localization. Making use of the information redundancy of CWT (Daubechies, 1992), we construct the FGWS by the following approach.

The CWT of a function, $f(t)$, is defined (Daubechies, 1992) as an integral transform

$$
W[f](a, b)=\int_{-\infty}^{\infty} f(t) \overline{\psi^{a, b}}(t) \mathrm{d} t
$$

where

$$
\psi^{a, b}(t)=\frac{1}{\sqrt{a}} \psi\left(\frac{t-b}{a}\right)
$$

thus

$$
W[f](a, b)=\int_{-\infty}^{\infty} \frac{f(t)}{\sqrt{a}} \overline{\psi\left(\frac{t-b}{a}\right)} \mathrm{d} t .
$$

The function $\psi(t)=\psi^{1,0}(t)$ is called the mother wavelet. It has to satisfy the admissibility condition

$$
C_{\psi}=2 \pi \int_{-\infty}^{\infty} \frac{|\psi(t)|^{2}}{|t|} \mathrm{d} t<\infty
$$

The inverse CWT then reads

$$
f(t)=\frac{1}{C_{\psi}} \int_{-\infty}^{\infty} \int_{\infty}^{\infty} \frac{W[f](a, b) \psi^{a, b}(t)}{a^{2}} \mathrm{~d} a \mathrm{~d} b,
$$

where the equality holds in the $L^{2}(\mathbb{R})$ sense. Some typical examples of wavelets are (e.g. Torrence and Compo, 1998):

$$
\begin{array}{ll}
\psi(t)=\frac{1}{\pi^{\frac{1}{4}}} \exp \left(i \omega_{0} t\right) \exp \left(-\frac{t^{2}}{2}\right) & \text { 'Morlet', } \\
\psi(t)=\frac{(-1)^{m+1}}{\sqrt{\Gamma\left(m+\frac{1}{2}\right)}} \frac{\mathrm{d}^{m}}{\mathrm{~d} t^{m}}\left[\exp \left(-\frac{t^{2}}{2}\right)\right] \text { 'DOG }_{m} \text { '. }
\end{array}
$$

'Morlet', (A6)

We employ only the discretized form of the CWT (not to be confused with the discrete wavelet transform, DWT), according to Torrence and Compo (1998). Given a discrete signal, $f_{n}=f(n \Delta t), n=0, \ldots, N-1$, and extended by zeros elsewhere, the discretized continuous wavelet spectrum (CWS) is defined by

$$
W_{n}[f](a)=\left(\frac{\Delta t}{a}\right)^{\frac{1}{2}} \sum_{j=0}^{N-1} f(j \Delta t) \overline{\psi\left[\frac{(j-n) \Delta t}{a}\right]} .
$$

The scales are taken in the form $a_{j}=a_{0} 2^{j} \delta j, j=0,1, \ldots, J$. The inverse transform then reads

$$
f_{n}=\frac{\delta j \sqrt{\Delta t}}{C_{\delta} \psi(0)} \sum_{j=0}^{J} \frac{\Re\left\{W_{n}[f]\left(a_{j}\right)\right\}}{\sqrt{a_{j}}},
$$

where $\Re$ denotes the real part and $C_{\delta}$ is the reconstruction factor (Torrence and Compo, 1998, table 2). Due to the time independence of the climatic forcing in the ISMIPHEINO experiments, after an initial transient period during which the glacier grows, the ice sheet becomes stabilized and switches semi-periodically between two threshold states: (1) an ice sheet of maximal volume with a frozen bed at the moment before the onset of sliding and (2) an ice sheet of minimal volume with the glacier base at the moment before refreezing. We employ scaled global (amplitude) wavelet spectrum (GWS), defined for the discretized CWS as

$$
\bar{W}^{2}[f](a)=\frac{\delta j \Delta t}{C_{\delta}} \frac{1}{N} \sum_{n=0}^{N-1}\left|W_{n}[f](a)\right|^{2},
$$

to give a stationary characteristic of the average ice-thickness time series (after the initial transient period).

For the numerical implementation, we use the Fortran code developed by Torrence and Compo (1998) (http://atoc. colorado.edu/research/wavelets/), which we slightly modify as follows. Given the signal

$$
f_{n}^{0}=f_{n} \quad n=0, \ldots, N-1,
$$

we initialize the FGWS estimate,

$$
F_{n}^{0}[f]=0,
$$

and construct a series of signals and their wavelet-spectra counterparts. Considering given $f^{k}=\left\{f_{n}^{k}\right\}_{n=0}^{N-1}$, for some $k$, we compute its discretized CWS, $W_{n}\left[f^{k}\right]\left(a_{j}\right)$, and evaluate the period $a_{j_{\max }}^{k}$ for which the GWS in Equation (A10) is maximal. A FGWS estimate at the $k$ th iteration is given as

$$
\begin{aligned}
& F_{n}^{k}[f]\left(a_{j_{\max }}^{k}\right)=F_{n}^{k-1}[f]\left(a_{j_{\max }^{k}}^{k}\right)+W_{n}^{k}\left[f^{k}\right]\left(a_{j_{\max }^{k}}^{k}\right), \\
& F_{n}^{k}[f]\left(a_{j} \neq a_{j_{\max }^{k}}^{k}\right)=F_{n}^{k-1}[f]\left(a_{j}\right) .
\end{aligned}
$$

The signal reconstruction at the $k$ th iteration is given by the inverse from the FGWS estimate according to Equation (A9):

$$
r_{n}^{k}=\frac{\delta j \sqrt{\delta t}}{C_{\delta} \psi(0)} \sum_{j=0}^{J} \frac{\Re\left\{F_{n}^{k}[f]\left(a_{j}\right)\right\}}{\sqrt{a_{j}}} .
$$

A new signal, $f^{k+1}$, is defined as the residuum

$$
f_{n}^{k+1}=f_{n}^{0}-r_{n}^{k} \quad n=0, \ldots, N-1 .
$$

We employ the statistical significance testing routines of Torrence and Compo (1998) and compare the wavelet power spectrum of the signal $f^{k}$ with the wavelet power spectrum of red noise with the same variance. The red noise is modelled by a lag- 1 autoregressive process, $x_{n+1}=\alpha x_{n}+z_{n}$, where $z_{n}$ is white noise and $\alpha$ is the autocorrelation, chosen as $\alpha=$ 0.99. The iterations stop when, with a statistical significance 


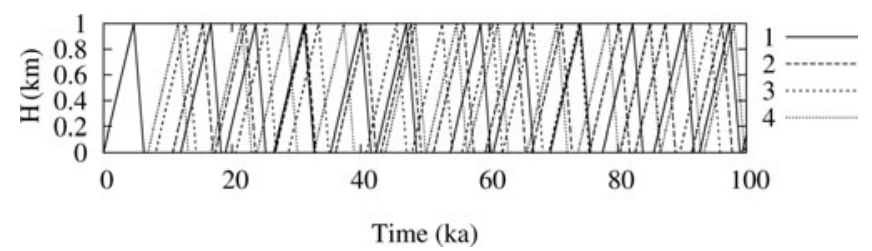

Fig. 15. Four realizations of the time series, $f(t)$, constructed from the shape functions, $S(t)$, separated by gaps of random (Gaussian) length.

$>95 \%$, the residual signal is just red noise. We call the resultant wavelet spectrum, $F^{k_{\max }}[f]$, the focused global wavelet spectrum (FGWS), because its spectral resolution, for the type of signal we are dealing with, is better spectrally localized than the CWS and focused around the maxima of CWS.

To demonstrate the procedure, we construct an auxiliary simple signal that bears the basic characteristics of the ISMIPHEINO average ice-thickness time series, and compare both the Fourier amplitude spectrum and the FGWS. Consider a shape function

$$
S(t)=\left\{\begin{array}{ll}
\frac{t-1}{3 T / 4-1} & \text { if } 0 \leq t \leq \frac{3 T}{4} \\
1-\frac{t-3 T / 4}{T / 4} & \text { if } \frac{3 T}{4} \leq t \leq T
\end{array},\right.
$$

for a given period $T$. Let the signal $f(t)$ be composed of the shape functions $S$ separated by gaps with a normal Gaussian distribution. In Figure 15 we show four different realizations of such a signal, and in Figure 16 a comparison of the Fourier amplitude spectrum (left) with the FGWS (right) is shown, demonstrating the focusing of the FGWS and distortion of the Fourier spectrum.
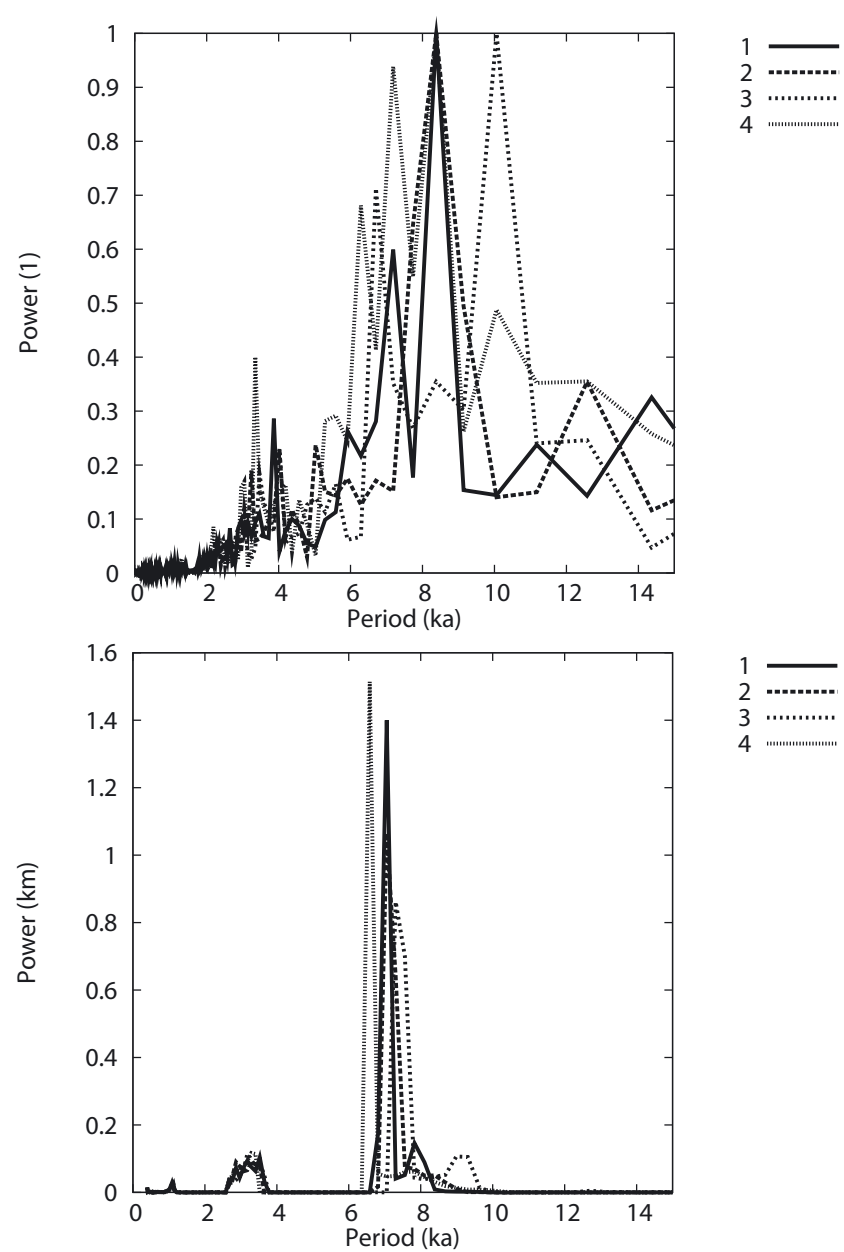

Fig. 16. The Fourier amplitude spectrum (top) and FGWS (bottom) for the time series in Figure 15. 